\title{
Blood pressure in a national birth cohort at the age of 36 related to social and familial factors, smoking, and body mass
}

\author{
M E J WADSWORTH, H A CRIPPS, R E MIDWINTER, J R T COLLEY
}

\begin{abstract}
Blood pressure was measured in a birth cohort of 5362 subjects at the age of 36. The prevalence of hypertension in men (blood pressure greater than $140 / 90 \mathrm{~mm} \mathrm{Hg}$ ) was almost twice that in women, although women received treatment more often. Deaths of fathers of subjects from hypertensive and ischaemic heart disease were associated with significantly higher mean systolic and diastolic pressures in both sexes. Cigarette smoking was not strongly associated with blood pressure in men and not associated at all in women. Of the social factors, low social class of family of origin was associated with high blood pressure in both sexes; but the strongest association was with current body mass, and birth weight also contributed.

Differences in blood pressures between the sexes may have been related to protective biological factors, such as endogenous sex hormones, in women and also to differences in types of employment, smoking habits, and body mass. Differences in blood pressures related to the social class of family of origin may reflect long term influences of class differences on diet, exercise, and educational achievement. The importance of measuring secular trends in obesity and blood pressures is emphasised.
\end{abstract}

\section{Introduction}

The rise in blood pressure with increasing age characteristic of urbanised countries is variously attributed to combinations of diet, smoking, exercise habits, obesity, and psychological tension and stress. ${ }^{12}$ Whatever the combination of factors, however, it seems generally accepted that their influence is slow and perhaps cumulative in effect.

Longitudinal and follow up studies of patients with high blood pressure, associated disorders, and probable predisposing conditions have been carried out in both Europe and North America. ${ }^{3-16}$ Most of these studies began when the populations studied were aged over 40, after the time when the slope of the rise in blood pressure first becomes steeper and habits more entrenched. ${ }^{717} 18$ In most of these investigations men only were studied, and all the studies relied on recollection for data from the vears before the studies started. Britain, however, has a unique national birth cohort study, which is a population sample of both men and women now aged $39 .{ }^{19}$ Data on many factors thought to be associated with increased risk of cardiovascular illness have been collected throughout the lives of all participants in the study, and when the subjects were aged 36 information was collected on blood pressure, pulse rate, diet, smoking, body mass, exercise, and stress.

We report the population distribution of blood pressure in the men and women in the cohort at the age of 36 and the association of blood pressure with contemporary and earlier social and family factors, body mass, and cigarette smoking.

Medical Research Council National Survey of Health and Development, Department of Epidemiology and Community Medicine, University of Bristol, Bristol BS8 2PR

M E J WADSWORTH, MPHIL, PHD, senior research fellow

H A CRIPPS, BSC, research assistant

R E MIDWINTER, MD, FFCM, consultant senior lecturer

J R T COLLEY, MD, FRCP, professor

Correspondence to: Dr Wadsworth

\section{Methods}

The prospective study reported here is the Medical Research Counci National Survey of Health and Development. The study population comprised 5362 subjects born in one week of March 1946 in England, Wales and Scotland and included all single, legitimate births to wives of non manual and agricultural workers and a randomly selected one in four sample of single, legitimate births to manual workers. ${ }^{19}$ The effect of sampling was compensated for in the data by weighting the results for randomly selected members of the study population by a factor of four. During childhood and adolescence the cohort was contacted every two years or less and in adult life about every five years. Data were collected by health visitors, teachers school doctors, and nurses during the early years and by interviewers an nurses in adult life. At each contact collection of data was as thorough as possible and usually included medical, psychological, social, occupationalio and family information. Losses through death and emigration reduced the sample to 3322 at age 36 , which was $85 \cdot 7 \%$ of the sample still resident ipo England, Wales, and Scotland. Comparisons with other data and subjecter born in the same week but who were not followed up showed that the cohorf was still representative of native born men and women of that generao tion. ${ }^{19}$

Information on blood pressurc, current smoking habits, and body mase reported here was recorded in the interviews conducted when subjects were aged 36, at which data were collected by 56 nurses trained by the surve staff. Many of the nurses had already acted as fieldworkers in the Medica Research Council's mild hypertension trial and had used the random zerf sphygmomanometer to record diastolic (phase V) blood pressure. All $5 \notin$ nurses were trained using tapes of Korotkoff sounds to ensure that systolie and diastolic (phase V) end points were recorded accurately. Blood pressureo was measured twice in $99.4 \%$ of the population visited, each time on the lef arm using a Hawkesley random zero sphygmomanometer and a regular siz\& $(12 \times 23 \mathrm{~cm})$ upper arm cuff. Measurements were taken at the end of an interview during which the subject had been seated for a median of $10 \Phi$ minutes. Systolic and diastolic (phase V) blood pressures were recorded, a well as time of day and ambient room temperature. Findings reported in thif paper used the second reading of blood pressure.

Maxwell et al showed that a cuff of inappropriate size for arn $\overrightarrow{\vec{\delta}}$ circumference may cause bias in readings of blood pressure, particularly in obese subjects, and found the regular cuff, as used in this study, to be more sensitive to changes in arm circumference than either the large arm cuff $(15 \times 33 \mathrm{~cm})$ or the thigh cuff $(18 \times 36 \mathrm{~cm})$; they noted underestimations of pressure with small arm circumference and overestimations with larges circumference. ${ }^{20}$ We therefore used the correction factors devised bs Maxwell et al, which were $32-(1.05 \times$ arm circumference in $\mathrm{cm})$ for systolie blood pressure and $22-(0.72 \times$ arm circumference in $\mathrm{cm})$ for diastolic bloọ. pressure.

Height was measured in $\mathrm{cm}$ to the nearest $0.5 \mathrm{~cm}$ below, and weight in $\mathrm{k}$ to the nearest $0.5 \mathrm{~kg}$ below. Body mass was computed using the body mas $\delta$ index (weight/height ${ }^{2}$ ). Type and quantity of cigarettes smoked were recorded to calculate intakes of tar, nicotine, and carbon monoxide using information supplied by the Department of Health. ${ }^{21}$

Pregnant women (30) were excluded from this analysis, and a further 32 subjects were excluded because of inconsistencies in measurements.

\section{Results}

BLOOD PRESSURE READINGS IN MEN AND WOMEN

Table I shows that systolic and diastolic blood pressures in men were higher than those in women in both the observed and the weighted populations; differences in observed means were also statistically significantत्D (systolic: $t=10 \cdot 21, \mathrm{p}<0.001$; diastolic: $t=7 \cdot 58, \mathrm{p}<0.001$ ). Maxwell's correc tion increased the proportion of subjects with diastolic blood pressures of 90 $\mathrm{mm} \mathrm{Hg}$ or over $(15 \cdot 5 \%$ of men with uncorrected diastolic pressures an $17 \cdot 2 \%$ after Maxwell's correction; corresponding figures for women weren $7 \cdot 4 \%$ and $9 \cdot 5 \%$ ). Analysis of variance showed that ambient room temperatureo (in $5^{\circ} \mathrm{C}$ increments) was not significantly associated with blood pressure. In 
BRITISH MEDICAL JOURNAL VOLUME 29130 NOVEMBER 1985

only two subjects, one of each sex, was there evidence of an underlying organic cause of blood pressure greater than $140 / 90 \mathrm{~mm} \mathrm{Hg}$.

Representative blood pressure measurements for a comparable population of men and women of this age were not available in Great Britain, but in comparison with findings in the United States this prevalence of diastolic pressure greater than $90 \mathrm{~mm} \mathrm{Hg}$ was low. ${ }^{22}$ The findings in the United States showed a rising secular trend in the percentages of men and women aged 25 34 with diastolic pressures greater than $90 \mathrm{~mm} \mathrm{Hg}$ between $1960-2(8 \cdot 7 \%$ of men studied and $5 \cdot 2 \%$ of women) and $1971-4(21 \cdot 4 \%$ of men and $9 \cdot 1 \%$ of women).

Table II shows the prevalence of recognition and treatment of hypertension (blood pressure greater than $140 / 90 \mathrm{~mm} \mathrm{Hg}$ ). Although hypertension
1535

was almost twice as common in men than women, it was much more often unrecognised, and therefore probably undiagnosed, in men, and twice as many women as men reported receiving treatment. The 51 subjects (observed population) receiving treatment were included in the following analysis.

\section{PARENTAL CIRCULATORY DISORDER}

Other studies found evidence of some degree of genetic determination and familial aggregation of blood pressure. ${ }^{23-26}$ As parental blood pressure had not been measured in this study a rough comparison between generations

TABLE I-Blood pressure readings for men and women in the observed and weighted populations

\begin{tabular}{|c|c|c|c|c|}
\hline & \multicolumn{2}{|c|}{ Observed population } & \multicolumn{2}{|c|}{ Weighted population } \\
\hline & $\begin{array}{l}\text { No }(\%) \\
\text { of men }\end{array}$ & $\begin{array}{c}\text { No }(\%) \\
\text { of women }\end{array}$ & Men $/ 1000$ & Women $/ 1000$ \\
\hline \multicolumn{5}{|c|}{ Systolic pressure $(\mathrm{mm} \mathrm{Hg})$} \\
\hline $\begin{array}{l}\leqslant 90.00 \\
90 \cdot 01-100 \cdot 00 \\
100 \cdot 01-110 \cdot 00 \\
110 \cdot 01-120 \cdot 00 \\
120 \cdot 01-130 \cdot 00 \\
130 \cdot 01-140.00 \\
140 \cdot 01-150 \cdot 00 \\
150 \cdot 01-160 \cdot 00 \\
160 \cdot 01-170 \cdot 00 \\
\geqslant 170.01\end{array}$ & $\begin{array}{rr}21 & (1 \cdot 3) \\
63 & (3 \cdot 9) \\
211 & (12 \cdot 9) \\
424 & (26 \cdot 0) \\
427 & (26 \cdot 2) \\
285 & (17 \cdot 5) \\
140 & (8 \cdot 6) \\
34 & (2 \cdot 1) \\
16 & (1 \cdot 0) \\
9 & (0 \cdot 6)\end{array}$ & $\begin{array}{rr}32 & (2 \cdot 0) \\
134 & (8 \cdot 3) \\
328 & (20 \cdot 4) \\
478 & (29 \cdot 7) \\
356 & (22 \cdot 1) \\
182 & (11 \cdot 3) \\
60 & (3 \cdot 7) \\
20 & (1 \cdot 2) \\
9 & (0 \cdot 6) \\
11 & (0 \cdot 7)\end{array}$ & $\begin{array}{r}15 \cdot 0 \\
34 \cdot 9 \\
127 \cdot 0 \\
246 \cdot 6 \\
275 \cdot 9 \\
178 \cdot 2 \\
89 \cdot 2 \\
20 \cdot 1 \\
6 \cdot 6 \\
6 \cdot 3\end{array}$ & $\begin{array}{r}18 \cdot 0 \\
77 \cdot 5 \\
202 \cdot 5 \\
290 \cdot 6 \\
2.0 \cdot 3 \\
111 \cdot 6 \\
35 \cdot 7 \\
12.4 \\
5.6 \\
7 \cdot 7\end{array}$ \\
\hline Total & $1630(100 \cdot 0)$ & $1610(100 \cdot 0)$ & & \\
\hline $\begin{array}{l}\text { Mean systolic pressure } \\
\text { Standard deviation }\end{array}$ & $\begin{array}{r}122 \cdot 93 \\
15 \cdot 01\end{array}$ & $\begin{array}{r}117 \cdot 50 \\
15 \cdot 25\end{array}$ & $\begin{array}{r}123 \cdot 10 \\
15 \cdot 02\end{array}$ & $\begin{array}{l}117 \cdot 64 \\
15 \cdot 15\end{array}$ \\
\hline \multicolumn{5}{|c|}{ Diastolic pressure $(\mathrm{mm} \mathrm{Hg})$} \\
\hline $\begin{array}{l}\leqslant 40 \cdot 00 \\
40 \cdot 01-50 \cdot 00 \\
50 \cdot 01-60 \cdot 00 \\
60 \cdot 01-70 \cdot 00 \\
70 \cdot 01-80 \cdot 00 \\
80 \cdot 01-90 \cdot 00 \\
90 \cdot 01-100 \cdot 00 \\
100 \cdot 01-110 \cdot 00 \\
110 \cdot 01\end{array}$ & $\begin{array}{rr}7 & (0 \cdot 4) \\
17 & (1 \cdot 0) \\
85 & (5 \cdot 2) \\
257 & (15 \cdot 8) \\
531 & (32 \cdot 6) \\
452 & (27 \cdot 7) \\
207 & (12 \cdot 7) \\
60 & (3 \cdot 7) \\
14 & (0 \cdot 9)\end{array}$ & $\begin{array}{rr}4 & (0 \cdot 2) \\
22 & (1 \cdot 4) \\
113 & (7 \cdot 0) \\
358 & (22 \cdot 2) \\
574 & (35 \cdot 7) \\
386 & (24 \cdot 0) \\
104 & (6 \cdot 5) \\
37 & (2 \cdot 3) \\
12 & (0 \cdot 7)\end{array}$ & $\begin{array}{r}5 \cdot 8 \\
10 \cdot 8 \\
51 \cdot 8 \\
157 \cdot 4 \\
328 \cdot 0 \\
270 \cdot 7 \\
133 \cdot 1 \\
34 \cdot 9 \\
7 \cdot 7\end{array}$ & $\begin{array}{r}2 \cdot 6 \\
13 \cdot 7 \\
64 \cdot 0 \\
222 \cdot 4 \\
348 \cdot 5 \\
236 \cdot 9 \\
64 \cdot 0 \\
21 \cdot 7 \\
7 \cdot 9\end{array}$ \\
\hline Total & $1630(100)$ & $1610(100)$ & & \\
\hline $\begin{array}{l}\text { Mean diastolic pressure } \\
\text { Standard deviation }\end{array}$ & $\begin{array}{l}78 \cdot 62 \\
12 \cdot 60\end{array}$ & $\begin{array}{l}75 \cdot 33 \\
12 \cdot 12\end{array}$ & $\begin{array}{l}78 \cdot 49 \\
12 \cdot 77\end{array}$ & $\begin{array}{l}75 \cdot 31 \\
11 \cdot 97\end{array}$ \\
\hline
\end{tabular}

TABLE II-Hypertension and its treatment: prevalence rates per 1000 weighted population

\begin{tabular}{|c|c|c|c|c|}
\hline & \multicolumn{2}{|c|}{$\operatorname{Men}(n=3787)$} & \multicolumn{2}{|c|}{ Women $(n=3782)$} \\
\hline & $\begin{array}{l}\text { Prevalence/ } 1000 \\
\text { weighted population }\end{array}$ & No & $\begin{array}{l}\text { Prevalence } / 1000 \\
\text { weighted population }\end{array}$ & No \\
\hline $\begin{array}{l}\text { Blood pressure } \geqslant 140 / 90 \mathrm{~mm} \mathrm{Hg} \\
\text { Recognised and treated hypertension and measured blood pressure }\end{array}$ & 78.95 & 299 & $40 \cdot 19$ & 152 \\
\hline$\geqslant 140 / 90 \mathrm{~mm} \mathrm{Hg}^{\star}$ & $9 \cdot 24$ & 35 & $8 \cdot 73$ & 33 \\
\hline $\begin{array}{l}\text { Unrecognised hypertension and measured blood pressure } \\
\geqslant 140 / 90 \mathrm{~mm} \mathrm{Hg} \\
\text { Recognised and treated hypertension but with measured blood pressure }\end{array}$ & $69 \cdot 71$ & 264 & $31 \cdot 46$ & 119 \\
\hline $\begin{array}{l}<140 / 90 \mathrm{~mm} \mathrm{Hg} \\
\text { Treated hypertension in those with measured blood pressure }\end{array}$ & $9 \cdot 24$ & 35 & $17 \cdot 98$ & 68 \\
\hline$\geqslant 140 / 90 \mathrm{~mm} \mathrm{Hg} \dagger$ & 2.90 & 11 & $4 \cdot 76$ & 18 \\
\hline
\end{tabular}

*Hypertension reported by patients themselves.

tThese subjects are also included in the first category.

TABLE III-Blood pressure of 36 year old men and women whose fathers had died of hypertensive or ischaemic heart disease compared with those whose fathers were still alive

\begin{tabular}{|c|c|c|c|c|}
\hline & \multicolumn{2}{|c|}{ Men } & \multicolumn{2}{|c|}{ Women } \\
\hline & \multicolumn{2}{|c|}{ Mean (SD) blood pressure in $\mathrm{mm} \mathrm{Hg}$} & \multicolumn{2}{|c|}{ Mean (SD) blood pressure in $\mathrm{mm} \mathrm{Hg}$} \\
\hline & Systolic & Diastolic & Systolic & Diastolic \\
\hline $\begin{array}{l}\text { Father dead of hypertensive or ischaemic heart disease } \\
\text { Father still alive } \\
t \text { test of difference in means }\end{array}$ & $\begin{array}{c}126.92(14.89) \\
(\mathrm{n}=164) \\
122 \cdot 36(14 \cdot 90) \\
(\mathrm{n}=944) \\
t=3.62, \mathrm{df}=\infty, \mathrm{p}<0.001\end{array}$ & $\begin{array}{c}80 \cdot 56(13 \cdot 65) \\
(\mathrm{n}=164) \\
78 \cdot 16(12 \cdot 34) \\
(\mathrm{n}=944) \\
t=2 \cdot 10, \mathrm{df}=\infty, \mathrm{p}<0.05\end{array}$ & $\begin{array}{c}121 \cdot 01(17 \cdot 82) \\
(\mathrm{n}=162) \\
116 \cdot 61(14 \cdot 90) \\
(\mathrm{n}=902) \\
t=2 \cdot 96, \mathrm{df}=\infty, \mathrm{p}<0.01\end{array}$ & $\begin{array}{c}77 \cdot 75(14 \cdot 29) \\
(\mathrm{n}=162) \\
74 \cdot 81(11 \cdot 47) \\
(\mathrm{n}=902) \\
t=2 \cdot 47, \mathrm{df}=\infty, \mathrm{p}<0 \cdot 02\end{array}$ \\
\hline
\end{tabular}


was made using reports of deaths of parents made by members of the study at the age of 36 , which were checked with death certificates. Deaths of fathers from hypertensive and ischaemic heart disease (International Classification of Disease $\left.\operatorname{codes}^{27} 401-5,410-4\right)$ amounted to $373(13 \cdot 6 \%)$, but deaths of mothers from these causes were relatively few (104) and therefore were not analysed. Men and women whose fathers had died of these diseases had significantly higher mean systolic and diastolic blood pressures than those whose fathers were still alive (table III). Mean blood pressures of those with fathers still alive compared with those of subjects whose fathers had died of other diseases were not significantly different.

The true association of parental circulatory illness with children's blood pressure remained unclear because of differences in the age and social class of the fathers $; 31.5 \%$ of fathers were still aged 60 years or younger when their children were 36 , and younger fathers were significantly more likely to be of manual social class.

\section{SOCIAL FACTORS}

Studies of blood pressure in men older than those in this study found that men in the lower social classes had significantly higher systolic and diastolic blood pressures than men in the non-manual social classes. ${ }^{328}$ In this study, although mean systolic pressures in men were highest in lower social classes (as defined by the Registrar General), there was no significant difference in class among subjects of either sex whose blood pressure was $140 / 90 \mathrm{~mm} \mathrm{Hg}$ or higher. There were no significant differences in social class between women related to mean systolic blood pressure or between men or women related to mean diastolic pressure.

A social class could not be recorded for $147(9 \%)$ men because of insufficient information, but the $107(6.6 \%$ of all men $)$ who were known to be unemployed had systolic and diastolic pressures more like those of men in social classes IV and V than others. Blood pressures of employed men and women, however, were not significantly different from those of the unemployed, even when unemployment was the result of illness.

In comparison with a study of another population of British men aged 4059 years social class differences in blood pressure in the present study were relatively small. ${ }^{2}$ This may be because the population we studied was younger. If this were the reason, and there was not only an increase in blood pressure with increasing age ${ }^{9}{ }^{29}$ but also an increase in difference between social classes in blood pressure with increasing age, then a more thorough investigation of social class would be required. In this study a more detailed investigation of social class was achieved by comparing the strength of associations with blood pressure of factors such as education, which are related to social class, and also by examining the association of change in social class with blood pressure.

The social circumstances of subjects' families of origin were determined using the social class of the father and the level of education achieved by each parent as an indicator of social group..$^{30}$ Men who had grown up in families in the lowest social group-that is, those with least educated parents and fathers of manual social class (663)-had significantly higher mean systolic pressures $(=123.43 \mathrm{~mm} \mathrm{Hg}$ ) than those with fathers of non-manual social group and well educated parents (180) (mean $119.33 \mathrm{~mm} \mathrm{Hg} ; t=3.53$, $\mathrm{df}=\infty, \mathrm{p}<0.001)$. Mean diastolic pressures of men from families in the lowest social group $(78.87 \mathrm{~mm} \mathrm{Hg})$ were also significantly higher than those of men from families in the highest social group (mean $76.26 \mathrm{~mm} \mathrm{Hg}$; $t=2 \cdot 67, \mathrm{df}=\infty, \mathrm{p}<0.01$ ).

Mean systolic blood pressures of men decreased significantly, however $(\mathrm{F}=7.62 ; \mathrm{p}<0.01)$, as their own educational qualifications increased, from a mean of $124.20 \mathrm{~mm} \mathrm{Hg}$ among those without qualifications to $121.01 \mathrm{~mm}$ $\mathrm{Hg}$ among those with university qualifications, but there were no differences in mean diastolic pressures. Of the men from families of manual social class who did not achieve any educational qualifications, those who rose within the manual classes in comparison with their fathers (93) had a significantly higher mean systolic blood pressure $(127.95 \mathrm{~mm} \mathrm{Hg})$ than those who had remained in the same manual class (149) $(123 \cdot 15 \mathrm{~mm} \mathrm{Hg} ; t=2 \cdot 23, \mathrm{df}=\infty$, $\mathrm{p}<0.05)$. This might have been associated with the stress of a rise in social class to jobs with an increased supervisory or management role without the benefit of educational qualifications. Evidence of increased stress under similar circumstances exists in an earlier study of this cohort. ${ }^{31}$ We shall examine this in detail in a later paper.

Because of the difficulty of ascribing social class to women, four measures were used-namely, social group of family of origin, social class of own current occupation, education, and employment status. There was no association between systolic or diastolic blood pressure and women's own social class. Women who came from families in the lowest social group (680) had significantly higher mean systolic pressures $(118.00 \mathrm{~mm} \mathrm{Hg})$ than women from families in the highest social group (181) $(114.60 \mathrm{~mm} \mathrm{Hg}$; $t=2.83, \mathrm{df}=\infty, \mathrm{p}<0.01)$ and also significantly higher mean diastolic pressures $(75.63 \mathrm{~mm} \mathrm{Hg})$ than those from families in the highest social group (mean $73.64 \mathrm{~mm} \mathrm{Hg} ; t=2.09, \mathrm{df}=\infty, \mathrm{p}<0.05$ ). There was no significant difference in blood pressure in women associated with employment status or educational achievement. Thus blood pressure in women was associated only with the social group of their family of origin.

\section{CIGARETTE SMOKING}

Roughly the same proportion of men and women reported that they were cigarette smokers at the age of $36(34 \cdot 1 \%$ and $33 \cdot 5 \%$, respectively), but more men than women smoked heavily $(11.6 \%$ of men and $5.2 \%$ of women smoked more than 20 cigarettes a day) and fewer men than women had never smoked $(18 \cdot 7 \%$ and $28 \cdot 6 \%$, respectively).

Men who smoked had a significantly higher mean systolic pressure than men who did not smoke $(t=2.49, \mathrm{df}=x, \mathrm{p}<0.02)$, but there was no difference in mean diastolic pressures. In women there were no significant differences in blood pressure between current smokers and non-smokers.

No significant association of current blood pressure with history of smoking during the preceding 16 years existed among men or women, whether they were current smokers or not.

In men who smoked diastolic pressure rose significantly as the number of cigarettes smoked daily increased (analysis of variance, $\mathrm{F}=4.58, \mathrm{p}<0.05$ ), but for women there were no significant associations with the number of cigarettes smoked. Men and women of manual social class who had jobs, however, had significantly higher daily doses of tar, carbon monoxide, and nicotine $(\mathrm{p}<0.01)$ (estimated in $\mathrm{mg}$ /day) because of their choice of cigarettes. Men and women who were not employed had doses of tar, carbon monoxide, and nicotine that did not differ significantly from those of the manual class of the same sex.

Multiple regression analysis showed that in men estimated daily doses of tar and nicotine were each significantly and independently associated with systolic blood pressure but not with diastolic. There were no significant associations of these components with systolic or diastolic pressure in women.

\section{OTHER FACTORS}

Birth weight was inversely associated with systolic but not diastolic pressure in men (analysis of variance $p<0.01)$ and women $(p<0.05)$.

In men mean body mass at the age of 36 rose from $23 \cdot 8$ in those who weighed less than $2721 \mathrm{~g}(6 \mathrm{lb})$ at birth (78), to $25 \cdot 1$ in those whose birth weight was $4535 \mathrm{~g}(10 \mathrm{lb}$ ) or more (61) (analysis of variance: $\mathrm{F}=19 \cdot 73$, $p<0.001)$. This trend was also found, but less significantly so, in women $(\mathrm{F}=3.92, \mathrm{p}<0.05)$

In both men and women mean systolic and diastolic blood pressures rose significantly with increasing body mass, as expected (table IV). ${ }^{32}{ }^{33}$ Compared with measurements taken when the cohort was aged 26 the proportion of overweight and obese men (using the Royal College of Physicians' definition $^{34}$ ) had increased considerably: at age $26,2 \cdot 3 \%$ of men were obese and $21 \cdot 2 \%$ overweight and at 36 the corresponding figures were $5 \cdot 3 \%$ and $37 \cdot 7 \%$ respectively. Using the same definition of obesity, the longer the women had

TABLE IV-Mean (SD) systolic and diastolic blood pressures by body mass for men and women grouped in tenths of population

\begin{tabular}{|c|c|c|}
\hline Body mass index & Systolic & Diastolic \\
\hline $\begin{array}{l}16 \cdot 1-20 \cdot 7(n=169) \\
20 \cdot 8-21 \cdot 9(n=148) \\
22 \cdot 0-22 \cdot 7(n=163) \\
22 \cdot 8-23 \cdot 4(n=149) \\
23 \cdot 5-24 \cdot 2(n=177) \\
24 \cdot 3-25 \cdot 0(n=163) \\
25 \cdot 1-25 \cdot 8(n=157) \\
25 \cdot 9-26 \cdot 8(n=161) \\
26 \cdot 9-28 \cdot 5(n=171) \\
28 \cdot 6-40 \cdot 3(n=158)\end{array}$ & $\begin{array}{c}\text { Men } \\
120 \cdot 44(14 \cdot 53) \\
122 \cdot 86(14 \cdot 36) \\
120 \cdot 71(13 \cdot 58) \\
121 \cdot 62(14 \cdot 03) \\
123 \cdot 25(15 \cdot 56) \\
122 \cdot 29(14 \cdot 42) \\
124 \cdot 70(16 \cdot 13) \\
121 \cdot 77(14 \cdot 93) \\
124 \cdot 35(13 \cdot 75) \\
127 \cdot 19(16 \cdot 68)\end{array}$ & $\begin{array}{l}73.81(13.92) \\
76.80(11.99) \\
77.45(10.86) \\
77.56(12.06) \\
78.53(12.67) \\
78.63(11.53) \\
78.88(11.04) \\
79.46(11.88) \\
82.01(12.95) \\
82.77(14.29)\end{array}$ \\
\hline $\begin{array}{l}14 \cdot 1-19 \cdot 4(n=154) \\
19 \cdot 5-20 \cdot 3(n=147) \\
20 \cdot 4-21 \cdot 0(n=171) \\
21 \cdot 1-21 \cdot 8(n=170) \\
21 \cdot 9-22 \cdot 4(n=153) \\
22 \cdot 5-23 \cdot 2(n=161) \\
23 \cdot 3-24 \cdot 2(n=163) \\
24 \cdot 3-25 \cdot 6(n=157) \\
25 \cdot 7-28 \cdot 1(n=164) \\
28 \cdot 2-47 \cdot 0(n=155)\end{array}$ & $\begin{array}{c}\text { Women } \\
117.22(13.69) \\
116.73(13.05) \\
118.06(13.40) \\
116 \cdot 18(14 \cdot 34) \\
115.02(13.68) \\
116.38(17 \cdot 18) \\
116.60(16.57) \\
117.76(14.98) \\
119.28(14.07) \\
121.25(19.84)\end{array}$ & $\begin{array}{l}75 \cdot 72(11 \cdot 31) \\
75 \cdot 31(11 \cdot 72) \\
75 \cdot 42(10 \cdot 11) \\
74 \cdot 47(11 \cdot 37) \\
73 \cdot 30(11 \cdot 06) \\
75 \cdot 14(12 \cdot 31) \\
73 \cdot 73(13 \cdot 72) \\
74 \cdot 76(12 \cdot 57) \\
77 \cdot 85(11 \cdot 23) \\
77 \cdot 58(14 \cdot 75)\end{array}$ \\
\hline
\end{tabular}

For men: $F=3.09, p=0.001$ (systolic); $F=6.95, p<0.001$ (diastolic); and for women $\mathrm{F}=2 \cdot 13, \mathrm{p}<0.03$ (systolic); $\mathrm{F}=2 \cdot 35, \mathrm{p}<0.02$ (diastolic). 
been obese the higher their systolic and diastolic pressures. The same tendency was also found in men's systolic pressure, but in neither sex was this statistically significant.

The association of both systolic and diastolic pressure with parity was essentially reverse $J$ shaped, although statistically significant differences were found only for systolic blood pressure in an analysis of variance $(\mathrm{F}=3.06, \mathrm{p}<0.05)$. Blood pressure was highest in nulliparous women aged $36(\mathrm{n}=210$, mean systolic $119.58 \mathrm{~mm} \mathrm{Hg}$, mean diastolic $76.61 \mathrm{~mm} \mathrm{Hg})$, followed by those who had had three or more children $(n=448$, mean systolic $117 \cdot 14 \mathrm{~mm} \mathrm{Hg}$, mean diastolic $75 \cdot 18 \mathrm{~mm} \mathrm{Hg}$ ), and lowest in women who had had two children $(\mathrm{n}=731$, mean systolic $116.59 \mathrm{~mm} \mathrm{Hg}$, mean diastolic $74.69 \mathrm{~mm} \mathrm{Hg}$ ).

Only 82 women $(5 \cdot 1 \%)$ reported taking oral contraceptives at the age of 36 , and this was taken to be under-reporting. When they were matched with women known to have been sterilised, however, there were no significan differences in means of either systolic or diastolic pressures, even when controlled for parity.

\section{COMBINED EFFECTS OF ASSOCIATED FACTORS}

Body mass, cigarette smoking, and blood pressure were each associated with the social factors. As Rose and Marmot hypothesised, the likelihood of being a non-smoker increased significantly with level of education in both men and women $(p<0.001)$, and the number of cigarettes smoked increased significantly the lower the social class in men $(p<0.001)$, but not in women. Men who had changed social class tended to have assumed the habits of the classes they had joined. Similarly, overweight and obesity were much more prevalent in the manual social classes and those with lowest educational achievement, and body mass index and birth weight were also associated with each other.

Stepwise multiple regression analyses were therefore used to test the degree of independence of association of the variables associated with blood pressure in each sex. As the estimates of intakes of nicotine, carbon monoxide, and tar were highly correlated with one another $(r=0.99$ at the least), a preliminary regression analysis was used to establish the precedence of tar intake as the prime factor associated with systolic blood pressure in men.

Table $\mathrm{V}$ shows that in both sexes and for both measures of blood pressure the contribution of social factors was found not to be significant after the effects of other factors, particularly current body mass and father's death from hypertensive or ischaemic heart disease, had been taken into account. When men and women who were receiving pharmacological treatment for hypertension were excluded from the analyses in table $\mathrm{V}$ the variables shown remained significantly associated with blood pressure, except in the case of diastolic pressure in women, where father's death was no longer significant. This suggests that those receiving treatment may have been predisposed genetically to hypertension.

\section{Discussion}

Differences in blood pressure between the sexes may have been partly the result of such apparently protective biological factors as endogenous sex hormones in women, but this was not estimated in our study. Prevalence of hypertension in men was almost twice that in women, but women were much more likely to be aware that they had the condition, and, as expected, to be receiving treatment. Differences between the sexes in types of employment, smoking habits, and body mass may also be important as shown in this study and elsewhere. ${ }^{3}$

Social class was significantly associated with blood pressure, which may reflect differences in psychological factors ${ }^{5}{ }^{36}{ }^{37}$ and habits. ${ }^{38}{ }^{39}$ Association with the social class of family of origin may also indicate long term effects of class differences in diet and exercise, which are probably offset to an extent by educational achievement, as we have also found in cigarette smoking.

The relatively modest association of current cigarette smoking (in the form of estimated daily intake of tar) with systolic pressure and the absence of an association of blood pressure with history of smoking were not entirely surprising, despite the known association of smoking with coronary heart disease. ${ }^{38-40}$ Members of this relatively young population, comprising a cohort born considerably later than most others reported, may have been less inclined to smoke heavily, because of the general population trend towards a reduction in smoking at younger ages. Recent studies show the need to take alcohol consumption into account when investigating blood pressure and smoking, ${ }^{40}$ and this will be possible later.

Current body mass was particularly important. This may also be subject to period effect, since the period during which members of the study grew up was characterised in Britain by a steady growth in the standard of living and purchasing power and a diet in which the proportion of energy derived from fat has continually increased. ${ }^{+1}+2$ Certainly men in the study experienced a considerable increase in overweight and obesity between the ages of 26 and 36 .

Forthcoming analyses will examine the association of blood pressure with psychological indicators and reported experience of stress and with dietary and exercise habits.

We hope to measure blood pressure in this population again later to investigate individual rates of change in blood pressure in relation to this first measurement ${ }^{9}$ and to examine change in blood pressure with age and length of exposure to risk factors. We hope particularly to discover whether women who at 36 experienced those factors associated with high blood pressure in men will have the highest and fastest rising blood pressures after the menopause and the consequent end of the apparent controlling effect of sex hormones on blood pressure.

The need for national data on secular trends in blood pressure is evident in the light of US findings, ${ }^{22}$ and the two younger British birth cohorts should, in due course, be able to supply some of the appropriate information..$^{43}$

\section{References}

1 Gampel B. Slome C, Scotch N. Abramson JH. Urbanization and hvpertension among Zulu adults. 7 Chront Dis 1962:15:67-70

Scotch N. Sociocultural factors in the epidemiology of Zulu hypertension. Am 7 Public Health $1963: 53: 1205-13$.

3 Shaper AG, Pocock SJ, Walker M, Cohen NM, Wale CJ, Thomson AG. British regional hear (t) 4 Rose G, Marmot M. Social class and coronary heart disease. Br Heart 7 1981;45:13-9.

TABLE V-Summary of the stepwise multiple regression analyses

\begin{tabular}{|c|c|c|c|c|c|}
\hline \multicolumn{3}{|c|}{ Dependent variable: systolic blood pressure $(\mathrm{mm} \mathrm{Hg})$} & \multicolumn{3}{|c|}{ Dependent variable: diastolic blood pressure $(\mathrm{mm} \mathrm{Hg})$} \\
\hline Variables in order of entry & $\begin{array}{l}\text { Regression } \\
\text { coefficient }\end{array}$ & $\mathrm{F}$ (significance) & Variables in order of entry & $\begin{array}{l}\text { Regression } \\
\text { coefficient }\end{array}$ & F (significance) \\
\hline $\begin{array}{l}\text { Men }(n=1396) \\
\text { Father's death from hypertensive/ } \\
\quad \text { ischaemic heart disease } \\
\text { Current body mass }\left(\mathrm{kg} / \mathrm{m}^{2}\right) \\
\text { Birth weight }(\mathrm{lb}) \\
\text { Tar dose }(\mathrm{mg} / \text { day }) \\
\text { Educational achievement } \\
\text { Social group of family of origin } \\
\text { Social class at age of } 36\end{array}$ & $\begin{array}{r}4.3465 \\
0.4749 \\
-1.0444 \\
0.0048\end{array}$ & $\begin{array}{r}13.09(\mathrm{p}<0.001) \\
15.05(\mathrm{p}<0.001) \\
9 \cdot 21(\mathrm{p}<0.010) \\
6.02(\mathrm{p}<0.050) \\
\text { (NS) } \\
\text { (NS) } \\
\text { (NS) }\end{array}$ & $\begin{array}{l}\text { Men }(n=1558) \\
\text { Current body mass }\left(\mathrm{kg} / \mathrm{m}^{2}\right) \\
\text { Father's death from hypertensive } \\
\text { ischaemic heart disease } \\
\text { Number of cigarettes smoked per day } \\
\text { Social group of family of origin }\end{array}$ & $\begin{array}{l}0.7139 \\
2 \cdot 1005\end{array}$ & $\begin{aligned} & 53.22(\mathrm{p}<0.001) \\
& 4.66(\mathrm{p}<0.050) \\
& \text { (NS) } \\
& \text { (NS) }\end{aligned}$ \\
\hline $\begin{array}{l}\text { Women }(n=1553) \\
\text { Current body mass }\left(\mathrm{kg} / \mathrm{m}^{2}\right) \\
\text { Father's death from hypertensive } \\
\text { ischaemic heart disease } \\
\text { Birth weight (lb) } \\
\text { Parity } \\
\text { Social group of family of origin }\end{array}$ & $\begin{array}{r}0 \cdot 3926 \\
3 \cdot 8295 \\
-0 \cdot 8953 \\
-2 \cdot 2456\end{array}$ & $\begin{aligned} & 16.97(\mathrm{p}<0.001) \\
& 10.62(\mathrm{p}<0.001) \\
& 6.18(\mathrm{p}<0.050) \\
& 3.88(\mathrm{p}<0.050) \\
&(\mathrm{NS})\end{aligned}$ & $\begin{array}{l}\text { Women }(n=1554) \\
\text { Current body mass }\left(\mathrm{kg} / \mathrm{m}^{2}\right) \\
\text { Father's death from hypertensive } \\
\text { ischaemic heart disease } \\
\text { Social group of family of origin }\end{array}$ & $\begin{array}{l}0 \cdot 2312 \\
2 \cdot 3572\end{array}$ & $\begin{array}{c}9.33(p<0.010) \\
6.38(p<0.050) \\
(\mathrm{NS})\end{array}$ \\
\hline
\end{tabular}


5 Theorell T, Floderus-Myrhed B. "Workload" and risk of myocardial infarction-a prospective psychosocial analysis. Int f Epidemiol 1977;6:17-21

6 Schroll M. A longitudinal epidemiological survey of relative weight at age 25, 50 and 60 in the Glostrup population of men and women born in 1914. Dan Med Bull 1981;28:106-16.

7 Miall WE, Chinn S. Screening for hypertension: some epidemiological observations. Br Med $\mathcal{J}$ 1974;iii:595-600.

8 Kornitzer MD, Dramaix M, Gheyssens $\mathrm{H}$. Incidence of ischaemic heart disease in two Belgian cohorts followed during 10 years. Eur 7 Cardiol 1979;6:455-72.

9 Svardsudd K, Tibblin G. A longitudinal blood pressure study. I Chronic Dis 1980;33:627-36.

10 Rosenman RH, Brand RJ, Jenkins CD, Friedman M, Straus R, Wurm M. Coronary heart disease in the western collaborative group study. Final follow-up experience of $8^{1 / 2}$ years. fAMA 1975;233:1000-9.

11 Haynes SG, Feinleib M, Kannel W'B. The relationship of psychosocial factors to coronary heart disease in the Framingham Study. III: eight-year incidence of coronary heart disease. Am $\mathcal{J}$ Epidemiol 1980;111:37-58.

12 Epstein FH, Napier JA, Higgins MW. The Tecumseh study: design, progress and perspectives. Arch Environ Health 1970;21:402-7.

13 Rabkin SW, Mathewson FAL, Ping-Hwa HSU. Relationship of body weight to development of ischaemic heart disease in a cohort of young North American men after a 26 year observation period: the Manitoba study. Am 7 Cardiol 1977;39:452-8

14 Rhoads GG, Kagan A. The relationship of coronary disease, stroke and mortality to weight in youth and middle age. Lancet $1983 ;$; :492-5.

15 Ekerdt DJ, Sparrow D, Glynn RJ, Bosse R. Change in blood pressure and total cholesterol with retirement. Am f Epidemiol 1984;120:64-7

16 Harlan WR, Oberman A, Mitchell W, Graybiel A. A thirty-year study of blood pressure in a white male cohort. Clinical Research 1971;19:319.

17 Hawthorne VM, Greaves DA, Beevers DG. Blood pressure in a Scottish town. Br Med $\mathrm{f}$ 1974;3:600-3.

18 Stone MC. The influence of age, sex and other risk factors. In: Hypertension in primary care. London: Roval College of General Practitioners, 1980. (Occasional Paper 12.

19 Atkins E, Cherry NM, Douglas JWB, Kiernan KE, Wadsworth MEJ. The 1946 British birth cohort: an account of the origins, progress and results of the National Survey of Health and Development. In: Mednick SA, Baert AE, eds. Prospective longitudinal research: an empirical basis for the primany prevention of psychosocial disorders. Oxford: Oxford University Press, 1981:25-30

20 Maxwell MH, Waks UA, Schroth PC, Karam M, Dornfeld LP. Error in blood-pressure measurement due to incorrect cuff size in obese patients. Lancet 1981;ii:33-6.

21 Health Departments of the UK. Tar, carbon monoxide and nicotine yields of cigarettes. London: HMSO, 1983. (TCN 3 .)

22 Roberts J, Maurer K. Blood pressure levels of persons 6-74 years in the United States, 1971-74 Washington DC: United States Department of Health Education and Welfare, National Centre for Health Statistics, 1977. (National Health Examination Survey, Series 11 No 203.)
23 Hurwich BJ, Rosner B, Nubani N, Ka EH, Lewitter FI. Familial aggregation of blood pressure in a highly inbred community, Abu Ghosh, Israel. Am f Epidemiol 1982;115:646-56.

24 Longini IM, Higgins MW, Hinton PC, Moll PP, Keller JB. Environmental and genetic source of familial aggregation of blood pressure in Tecumseh, Michigan. Am f Epidemiol 1984;120:13144.

25 Miall WE, Oldham PD. The hereditary factor in arterial blood pressure. Br Med $\mathcal{f}$ 1963;2:75-80. 26 Oberman A, Lane NE, Harlan WR, Graybiel A, Mitchell RE. Trends in systolic blood pressure in the thousand aviator cohort over a twenty four year period. Circulation 1967;36:812-22.

27 World Health Organisation. International classification of diseases. 9th revision, 1975. Vol 2 Geneva: WHO, 1978.

28 Marmot MG, Adelstein AM, Robinson N, Rose GA. Changing social-class distribution of heart disease. BrMed f 1978;2:1109-12.

29 Marmot MG. Culture and illness: epidemiological evidence. In: Christie MJ, Mellett P, eds. Foundations of psychosomatics. London: John Wiley, 1981:323-40.

30 Douglas, JWB. The home and the school. London: McGibbon and Kee, 1964.

31 Cherry N. Stress, anxiety and work. A longitudinal study. Fournal of Occupational Psych 1978;51:259-70.

32 Kagan A, Gordon T, Rhoads GG, Schiffman JC. Some factors related to coronary heart disease incidence in Honolulu Japanese men: the Honolulu heart study. Int f Epidemiol 1975;4:271-9.

33 Jarret RJ, Shipley MJ, Rose G. Weight and mortality in the Whitehall study. Br Med 7 1982;285:535-7.

34 Royal College of Physicians. Obesity. I R Coll Physicians Lond 1983;17:5-65.

35 Waldron I. Sex differences in illness incidence, prognosis and mortality. Soc Sci Med 1983;17:1107-23.

36 Jenkins CD. Low education: a risk factor for death. $N$ Engl 7 Med 1978;299:95-6.

37 Haynes SG, Levine S, Scotch N, Feinleib M, Kannel WB. The relationship of psychosocial factors to coronary heart disease in the Framingham study. I: methods and risk factors. Am $\mathcal{F}$ Epidemio 1978;107:362-83.

38 Savdie E, Grosslight GM, Adena MA. Relation of alcohol and cigarette consumption to blood pressure and serum creatinine levels. $\mathcal{F}$ Chronic Dis 1984;37:617-23.

39 Reid DD, Hamilton PJS, McCartney P, Rose G, Jarret RJ, Keen H. Smoking and other risk factors for coronary heart disease in British civil servants. Lancet 1976;ii:979-84.

40 United States Surgeon General. The health consequences of smoking: cardiovascular disease. Rockville: Department of Health and Human Services, 1983.

41 Central Statistical Office. Social trends. London: HMSO, 1972 et seq.

42 Department of Health and Social Security. Diet and cardiovascular disease. London: HMSO, 1984 Reports on Health and Social Subjects, No 26.

43 Wadsworth MEJ, Peckham CS, Taylor B. The role of national longitudinal studies in the prediction of health, development and behaviour. In: Walker DK, Richmond JB, eds. Monitoring child health in the United States. Cambridge, Massachussets: Harvard University Press, 1984:63-83.

(Accepted 25 September 1985)

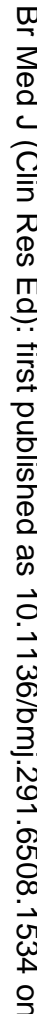

\section{SHORT REPORTS}

\section{Helping people to stop smoking: randomised comparison of groups being treated with acupuncture and nicotine gum with control group}

The two treatments most often studied in helping people to stop smoking are acupuncture ${ }^{2}$ and nicotine gum. ${ }^{3+}$ We report the results of a randomised trial comparing the efficacy of these treatments with that of a control treatment over 12 months of follow up.

\section{Subjects, methods, and results}

We advertised among the general public asking for volunteers to participate in the trial. Although a recent poll reported that almost half the smokers in France wished to stop smoking, we had to contact nearly 35000 smokers to enrol 651
The criteria for success were the proportion of people who had completely stopped smoking one and 13 months after entering the study and evolution of this proportion.

Subjects who claimed to have stopped smoking were followed up by post every three months after stopping. Those still smoking after one month were not followed up afterwards and were counted as failures, as were non-respondents to mailings sent to those who did not attend the third group therapy session. Half of the ex-smokers were visited at home at one year and their expired carbon monoxide concentration measured (carbon monoxide breath kit, Catalyst Research Corporation). Concentrations greater than five parts per million were attributed to smoking. We estimated that 200 participants in each group were necessary to show a reduction in the prevalence of smoking after one month from $75 \%$ in the control group to $60 \%$ in the active treatment groups $(\alpha=5 \%, \beta=10 \%)$.

Altogether 224 subjects were given acupuncture, 205 nicotine gum, and 222 the control treatment. No significant difference was found between the three groups for sex, age, age at first cigarette, daily consumption, previous attempts to stop smoking, and frequency of inhalation. The proportion of non-respondents (about 6\%) did not differ between the three groups. None among those whose exhaled concentration of carbon monoxide was checked was found to be smoking. The proportion of ex-smokers at one and 13 months was significantly lower in the

No (\%) of ex-smokers one and 13 months after entry to study by treatment group

\begin{tabular}{|c|c|c|c|c|c|c|c|}
\hline & \multirow{2}{*}{$\begin{array}{l}\text { Acupuncture } \\
\quad(n=224)\end{array}$} & \multirow{2}{*}{$\underset{(n=205)}{\text { Gum }}$} & \multirow{2}{*}{$\begin{array}{l}\text { Control } \\
(n=222)\end{array}$} & \multicolumn{4}{|c|}{$\mathrm{p}$ Values of tests } \\
\hline & & & & Global & Acupuncture $v$ control & Gum $v$ control & Acupuncture $v$ gum \\
\hline $\begin{array}{l}\text { At one month } \\
\text { At } 13 \text { months }\end{array}$ & $\begin{array}{l}43(19) \\
17(8)\end{array}$ & $\begin{array}{l}46(22) \\
24(12)\end{array}$ & $\begin{array}{r}18(8) \\
6(3)\end{array}$ & $\begin{array}{l}0.0001 \\
0.002\end{array}$ & $\begin{array}{l}0.001 \\
0.02\end{array}$ & $\begin{array}{l}0.00001 \\
0.001\end{array}$ & $\begin{array}{l}\text { NS } \\
\text { NS }\end{array}$ \\
\hline
\end{tabular}

participants. Adults smoking at least five cigarettes a day were eligible. We excluded women who were pregnant or breast feeding and people with gastric ulcers or a history of heart disease. Treatment (acupuncture, nicotine gum, or a control treatment) was allocated by balanced randomisation, each group receiving three one hour sessions of group therapy during the first month.

In the group given acupuncture the needles were placed bilaterally for 30 minutes at the "shuai gu" and "qiuhou" points. In the group given nicotine gum 105 pieces of gum, each containing $2 \mathrm{mg}$ nicotine, were distributed to each participant. Subjects in the control group were given minimal intervention, consisting of a cigarette case with a lock controlled by a time switch, which they could regulate at will. control group than in the groups given acupuncture and gum (table). The evolution of this proportion throughout the follow up period showed no significant difference between the three groups.

\section{Comment}

The groups given acupuncture and nicotine gum showed a better response than the control group. The lack of difference between the two active treatments may have been due to a lack of power: the number of subjects was 